\title{
Identifying the impact of multi-hazards on crop yield-A case for heat stress and dry stress on winter wheat yield in northern China
}

\author{
Yi Chen ${ }^{a}$, Zhao Zhang ${ }^{a, *}$, Pin Wang ${ }^{a}$, Xiao Song ${ }^{a}$, Xing Wei ${ }^{a}$, Fulu Tao ${ }^{b}$ \\ a State Key Laboratory of Earth Surface Processes and Resources Ecology, Academy of Disaster Reduction and Emergency Management, Beijing Normal \\ University, Beijing 100875, China \\ ${ }^{\mathrm{b}}$ Institute of Geographical Sciences and Natural Resources Research, Chinese Academy of Sciences, Beijing 100101, China
}

\section{A R T I C L E I N F O}

\section{Article history:}

Received 3 October 2014

Received in revised form 17 October 2015

Accepted 27 October 2015

Available online 17 November 2015

\section{Keywords:}

Northern China

Heat stress

Dry stress

Adaptation

Winter wheat

\begin{abstract}
A B S T R A C T
Winter wheat production in northern China severely suffered from high temperatures and low relative humidity. However, the spatio-temporal pattern of heat stress and dry stress and the impacts of these multi-hazards on winter wheat yield have rarely been investigated. Using historical climate data, phenology data and yield records from 1980 to 2008, an analysis was performed to characterize the spatio-temporal variability of heat stress and dry stress in the post-heading stages of wheat growth in northern China. Additionally, these stresses' impacts on winter wheat yield fluctuations were evaluated. Spatially, the central and northern parts of northern China have seen more serious heat stress, while greater dry stress has been observed in the northwest and north of the research area. Temporally, the heat stress has increased in the western part but decreased in the central and eastern parts of research area. Dry stress has aggravated in the entire northern China during the past decades, indicating the complexity of the exposure to adverse climate conditions. These two hazards (heat stress and dry stress)

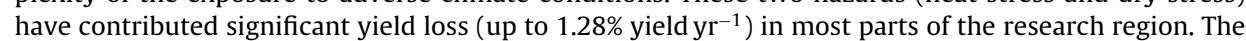
yield in the west was more sensitive to heat stress, and dry stress was the main hazard in the south. Additionally, the opposite spatial pattern between the sensitivity and exposure revealed that the climate is not the only factor controlling the yield fluctuation, the local adaptation measures used to mitigate negative influences of extreme events should not be ignored. In general, this study highlighted a focus on the impacts of multi-hazards on agricultural production, and an equal importance of considering local adaptation ability during the evaluation of agricultural risk in the future. Additionally, paying more attention to higher sensitive areas and to more reasonable and practical adaptive strategies is critical and significant for food supply security.
\end{abstract}

(c) 2015 Elsevier B.V. All rights reserved.

\section{Introduction}

Ongoing climate change impacts agricultural production because of the increase of temperature, carbon dioxide concentration and the changes in precipitation patterns (Li et al., 2010). Meanwhile, the increasing incidence and intensity of extreme climate events, such as extreme high-temperatures, droughts and floods have severely threatened crop growth (Decker, 1994; Zhang et al., 2010; Zhang et al., 2014a; IPCC, 2012; Wang et al., 2014). The quantification of extreme events' impacts on agricultural outputs and the uncertainty, variability and error propagation during risk evaluation have drawn more concerns since AR4 (Porter et al.,

\footnotetext{
* Corresponding author. Tel.: +86 1058805461 .

E-mail address: zhangzhao@bnu.edu.cn (Z. Zhang).
}

2014). In many studies, high temperature stress is regarded as the most critical factor impacting the crop yield and quality (Rane and Nagarajan, 2004; Lobell et al., 2011; Asseng et al., 2011; Semenov et al., 2012). Exposure to extreme high temperatures for a few hours could drastically reduce the crop yield (Randall and Moss, 1990; Porter and Gawith, 1999; Tao et al., 2013). Thus, more attentions are now paid to the influence of extreme high temperatures on different types of crops (Stone and Nicolas, 1994; Deryng et al., 2014; Asseng et al., 2015). In addition to extreme temperature stress, other combined climate variables in extreme events, such as extreme low relative humidity (Lobell et al., 2011), also play important roles in restricting crop growth. However, attentions on these variables are insufficient. Most of the studies are oblivious to the impacts of multi-hazards (e.g., dry heat, humid heat) in extreme events. The analyses focusing on a single extreme climate variable may not be convincing enough to characterize the entire impact of 
extreme events, and influence our understanding of comprehensive risk of extreme events for food supply security.

As one of the major food crops in China, wheat accounted for $21.9 \%$ of the total sowing area of crops in 2011 (National Bureau of Statistics of China, 2011), which makes China the largest wheatproducing country in the world (FAO, 2012). The sensitive period for wheat growth to extreme climate conditions is the post-heading reproductive stages. It is in these stages that climate conditions drive the grain number per $\mathrm{m}^{2}$ and average grain weight, which determine the yield (Ugarte et al., 2007). During these stages, the dominant agro-meteorological disaster in northern China is dryhot wind. As a typical multi-hazards-disaster, this disaster involves the concurrent of two extreme climate variables, including a daily maximum temperature greater than $30^{\circ} \mathrm{C}$ and a daily minimum relative humidity less than $30 \%$ (Deng et al., 2009). The noticeable effect of the dry-hot wind, which can lead to the crop failure for $5-20 \%$ of the annual production, has been concerned for many years, especially after 1988 when the coordination research group of dry-hot wind for wheat in northern China was established. Previous domestic research have characterized the spatio-temporal distribution of dry-hot wind using the disaster records in a limited geographic area (e.g., a single county, or province), or evaluated the responses of winter wheat to the disaster by conducting field experiments (Cao and Dou, 1997; Cheng et al., 2011; Yang et al., 2013; Zhang et al., 2014b). These studies have clearly stated that temperature is the pivotal variable controlling the winter wheat growth, and the effects of humidity are also significant in that low humidity would further aggravate the impacts of heat stress (Liu et al., 2008; Gourdji et al., 2013). However, few studies have quantified the impacts of both climatic variables (heat and dry) on winter wheat production using long-term historical climate and yield records. Therefore, it is still difficult to diagnose the comprehensive risk from extreme climate conditions on winter wheat growth in northern China.

Additionally, when assessing the influences of climate change on crop yield, adaptation should also be accounted for because of its crucial effect on mitigating the negative impacts of extreme events (Bryan et al., 2009; Reidsma et al., 2010). Evaluation on the exposure of extreme events and the effects of adaptation are both essential for better understanding agricultural risks from climate changes. Thus, we should pay attention to the vulnerability of crop and identify the areas with high risk of yield loss.

In this study, our aims were to: (1) characterize the spatiotemporal distribution of indexes describing heat and dry stress in post-heading stages of winter wheat during the past 30 years in northern China, (2) characterize the changes of detrended yields in research regions, and (3) evaluate the impacts of heat and dry stress and adaptations on the observed winter wheat yield.

\section{Data and methods}

\subsection{Study region and data source}

Our study area covered six main winter wheat producing provinces in northern China (National Bureau of Statistics of China, 2011) (Fig. 1a). Observed daily climate datasets were collected from 50 meteorological stations in this region to calculate climate indexes. County-level data of winter wheat yield $\left(\mathrm{kg} \mathrm{ha}^{-1}\right)$ in the region were collected from the Agricultural Yearbook of each county (published annually by the China Agriculture Press in Beijing), and some unpublished records from local county bureau of statistics as mentioned in Tao et al. (2012) from 1980 to 2008. Phenology data from 70 agro-meteorological stations were used to identify the local specific sensitive period for each county (Fig. 1b).

\subsection{Yield data detrending}

The winter wheat yield data were preprocessed to control the data quality. For time series of yield in each county, the mean and standard deviation were calculated. The outliers were defined as the data points that fell outside the range of mean value \pm two times of standard deviation (Zhang et al., 2014). These outliers were then removed.

To assess the influence of climate change on winter wheat yield, the impacts of technological progresses on yields should be removed. Because of the local-specific characteristics of climate conditions, soil, management etc., the technological yield may vary among different counties. In this study, we adopted the method proposed by Ray et al. (2012). For the time series of yield in each county, four regression models, including the intercept-only model, linear model, quadratic model and cubic model, were fitted. The best model was chosen based on the Akaike Information Criterion (Akaike, 1974) and F-test. This model can best represent the yield trend and was then used to calculate the technological yield series for this county. Additionally, the ratio of detrended yield was calculated as the difference ratio between technological yield and actual yield relative to the technological yield (Eq. (1)).

$R=\frac{Y_{\mathrm{A}}-Y_{\mathrm{T}}}{Y_{\mathrm{T}}} \times 100 \%$

where $R$ is the ratio of detrended yield, and $Y_{\mathrm{A}}$ and $Y_{\mathrm{T}}$ are the actual yield and technological yield, respectively.

\subsection{Defining climate indexes}

This study focused on the sensitive periods of winter wheat to dry heat stress, which was from the heading stage to the maturity stage (post-heading stages). The dates of these two stages from 1980 to 2008 were processed using spatial interpolation in ArcGIS 9.3 to identify the heading date and maturity date at each meteorological station. Climate dataset during the sensitive periods were used to calculate the climate indexes.

Four indexes were developed to characterize the dry heat stress. We defined accumulated heat stress $\left(G D_{\text {heat }}\right)$ as the annual accumulated heat degree days when the daily maximum temperature was greater than $30^{\circ} \mathrm{C}$ in post-heading stages using Eqs. (2) and (3). The intensity of $\mathrm{GDD}_{\text {heat }}$ (named as $\mathrm{GDD}_{\text {heat }} \mathrm{I}$ ) was calculated as the daily average $\mathrm{GDD}_{\text {heat }}$ for days suffering from heat stress (Eq. (4)).

$\mathrm{GDD}_{\text {heat }}=\sum_{d h}^{d m} H S_{i}$

$H S_{i}=\left\{\begin{array}{lc}0 & T_{\text {maxi }}<T \\ T_{\text {maxi }}-T & T_{\text {maxi }} \geq T\end{array}\right.$

$\mathrm{GDD}_{\text {heat }} \mathrm{I}=\frac{\mathrm{GDD}_{\text {heat }}}{n}$

In these equations, the $d h$ and $d m$ are the dates of the heading stage and maturity stage at the meteorological stations, respectively. $H S_{i}$ is the heat stress for days with a maximum temperature $\left(T_{\operatorname{maxi}}\right)$ greater than $T$ (threshold of $30^{\circ} \mathrm{C}$ ), $\mathrm{GDD}_{\text {heat }}$ is the accumulation of $H S_{i}$ from the heading stage to the maturity stage, and $n$ is the number of days with a daily maximum temperature greater than $30^{\circ} \mathrm{C}$.

The other two indexes were developed for dry stress. An annual accumulated deficit of humidity (HDD) was calculated as the sum of the differences between the actual relative humidity and a threshold of $30 \%$ during heat stress days using Eq. (5). The intensity of HDD 


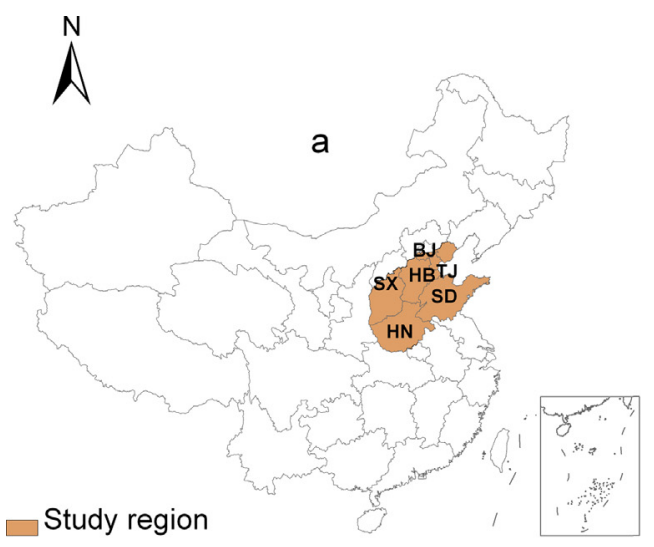

- Agro-meteorological stations(Phenology)

ـ Meteorological stations

Typical counties

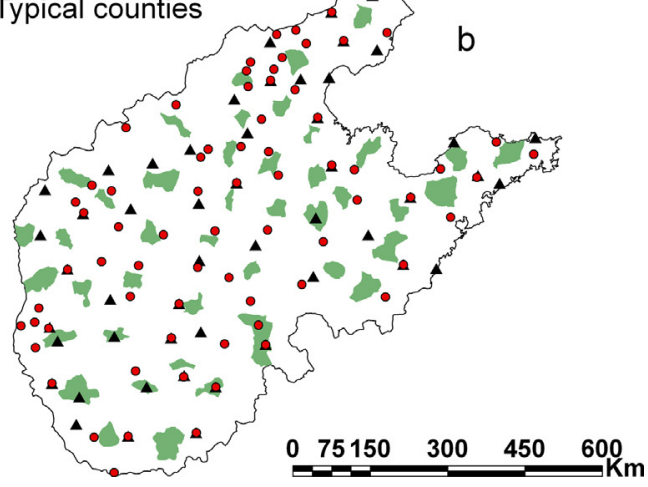

Fig. 1. The location of study region (a), agro-meteorological stations, meteorological stations and typical counties (b).

(HDDI) was calculated as the daily average HDD for days suffered from heat stress using Eq. (6).

$$
\begin{aligned}
\mathrm{HDD} & =\sum_{d h}^{d m} H-H_{\text {min }} \\
\mathrm{HDDI} & =\frac{\mathrm{HDD}}{n}
\end{aligned}
$$

where $H_{\min }$ is the daily minimum relative humidity and $H$ is the threshold of relative humidity (30\%). $d h, d m$ and $n$ are the same as for Eq. (2). The negative values of HDD were kept, suggesting there was no dry stress during a hot event.

\subsection{Characterizing the spatio-temporal pattern of climate indexes}

Climate index averages at each meteorological station from 1980 to 2008 were analyzed to identify their spatial variation. Regarding temporal trends during the same period, the indexes from 1980 to 2008 were linearly fitted, and the slopes of the fitted equations were used as indicators. The changes of indexes were labeled by adding a letter " $C$ " at the end. For example, the change of $\mathrm{GDD}_{\text {heat }}$ was named $\mathrm{GDD}_{\text {heat }} \mathrm{C}$. The spatial interpolation in ArcGIS 9.3 was used to display the spatio-temporal patterns.

\subsection{Identifying the influence of dry and heat stress on wheat yield}

The climate indexes in each county were computed from the nearest meteorological stations (Tao et al., 2012). We selected $\mathrm{GDD}_{\text {heat }}$ and HDD as variables because they contained extreme events durations and annual intensities (Zhang et al., 2014c). In total, 44 sample counties were selected according to the following criteria: (a) these counties frequently suffered from heat stress, (b) the yield and corresponding climate records spanned more than 20 years, and (c) the counties are distributed evenly around the study region (Fig. 1b). Eq. (7) was applied to identify the impact of heat and dry stress on the winter wheat yield. Linear correlation analyses were also applied to fit the relationships between the detrended yield and $\mathrm{GDD}_{\text {heat }}$ or HDD alone.

$R=\beta_{0}+\beta_{1} \mathrm{GDD}_{\text {heat }}+\beta_{2} \mathrm{HDD}+\epsilon$

In Eq. (7), $R$ is the ratio of the detrended yield (the same in equation (1)), $\beta_{0}$ is the intercept of the regression model, $\beta_{1}$ and $\beta_{2}$ are the coefficients for the corresponding climate indexes used to indicate the sensitivities of the yield to climate indexes, and $\varepsilon$ is the error of model. The previously mentioned regression models were developed at both county and regional scales to comprehensively identify the responses of wheat yield to extreme events. We then multiplied the sensitivities of yield to the local-specific trend of each climate index to quantify the contribution of climate change to the county-level yield. The overall contribution was calculated by summing the contributions of $\mathrm{GDD}_{\text {heat }}$ and HDD.

Additionally, the negative fluctuation of detrended yield in sample counties was used to evaluate the adaptation to climate changes (Yang et al., 2013). The smaller crop failure indicated that the local yield was more stable and suffered less from climate changes because of efficient adaptation methods. On the contrary, a larger crop failure indicated a larger yield fluctuation that was resulted from the lack of adaptation ability. Because the number of yield failure records varied in different counties, the average of crop failure was used as the indicator.

\section{Results}

\subsection{Spatio-temporal pattern for climate indexes}

The spatial patterns of four climate indexes are presented in Fig. $2 \mathrm{a}$ and $\mathrm{b}$ and Fig. $3 \mathrm{a}$ and $\mathrm{b}$. During the past 30 years, the spatial distribution of the average value of $\mathrm{GDD}_{\text {heat }}$ showed a distinct regional difference. The exposure of winter wheat yield to heat stress was highest in the central and northern region of the study area $\left(>35^{\circ} \mathrm{Cd}\right)$, and secondary in the west and southwest $\left(25-35^{\circ} \mathrm{Cd}\right)$. Relatively lower exposure occurred in the south and east $\left(0-25^{\circ} \mathrm{Cd}\right)$. The significant high heat stress occurred in the main areas of the HB province (Fig. 2a). Similar results occurred for the spatial pattern of $G D_{\text {heat }} I$ (Fig. 3a). The highest $G D_{\text {heat }} I$ of $2.89^{\circ} \mathrm{C}$ in the middle of $\mathrm{HB}$ indicated an average daily highest temperature of $32.89^{\circ} \mathrm{C}$, which was $1.94^{\circ} \mathrm{C}$ higher than the lowest value of $0.95^{\circ} \mathrm{C}$ in eastern part of the SD province during heat stress events.

The dry stress showed different spatial patterns compared to that of heat stress in the research region. Relatively wetter climate conditions appeared at low latitudes, and severe dry environments in the northern and northwest of the study area. The accompanying dryness during heat stress was prevalent in most of the study area, substantiating that wheat growth would suffer from multihazards, including heat and dry stress. The driest area was located in the northern part of the SX province, where an HDDI of more than $9 \%$ indicated a daily lowest average relative humidity condition less than $21 \%$. In comparison, negative HDD and HDDI values in southern HN and western SD manifested relatively wetter environments during heat stress days. The daily average relative humidity of $30-36 \%$ indicated a weaker dry stress than other parts of the region, implying less exposure to multi-hazards. 

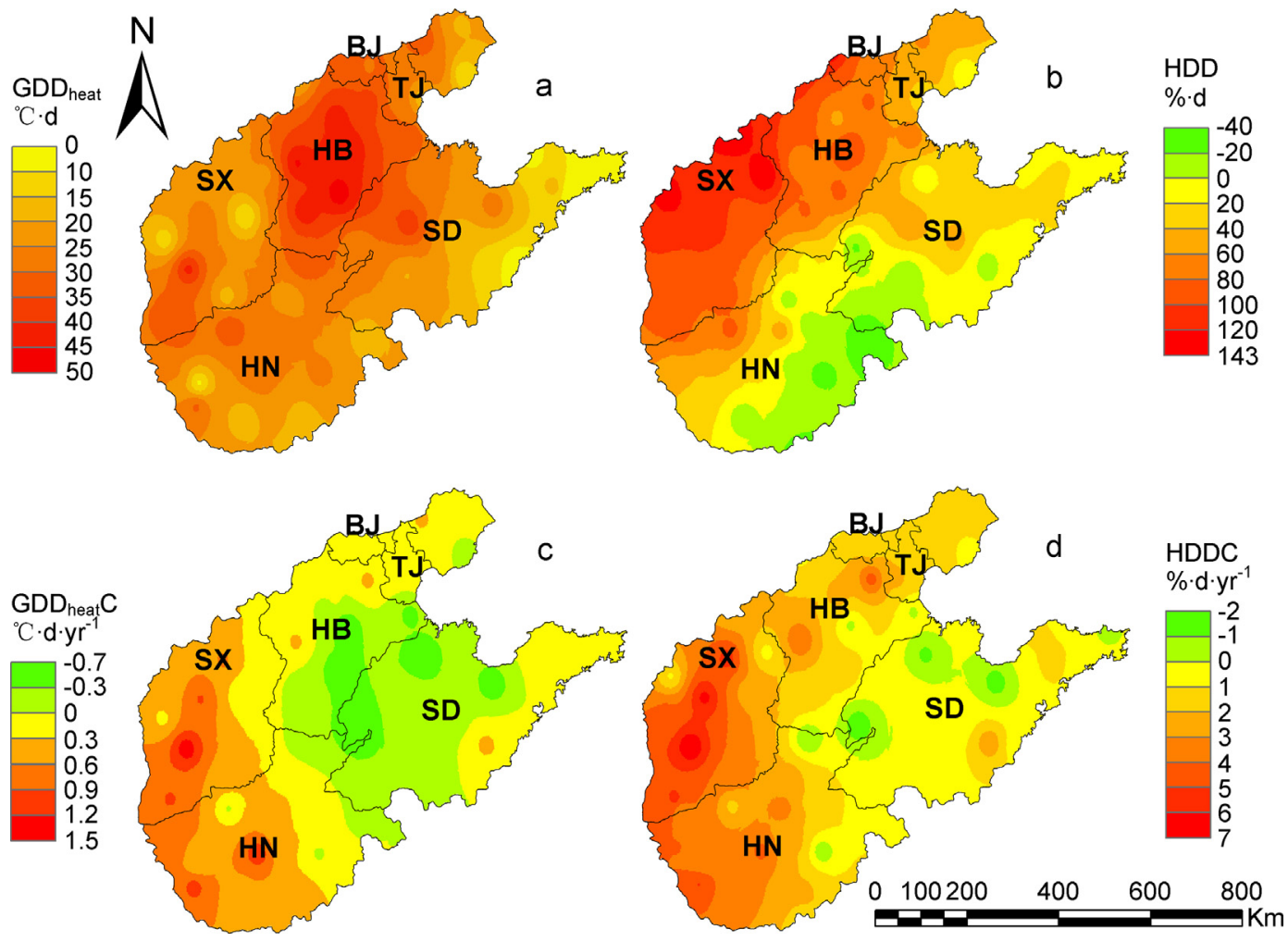

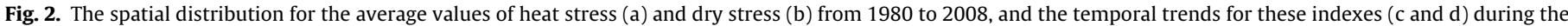
same period.
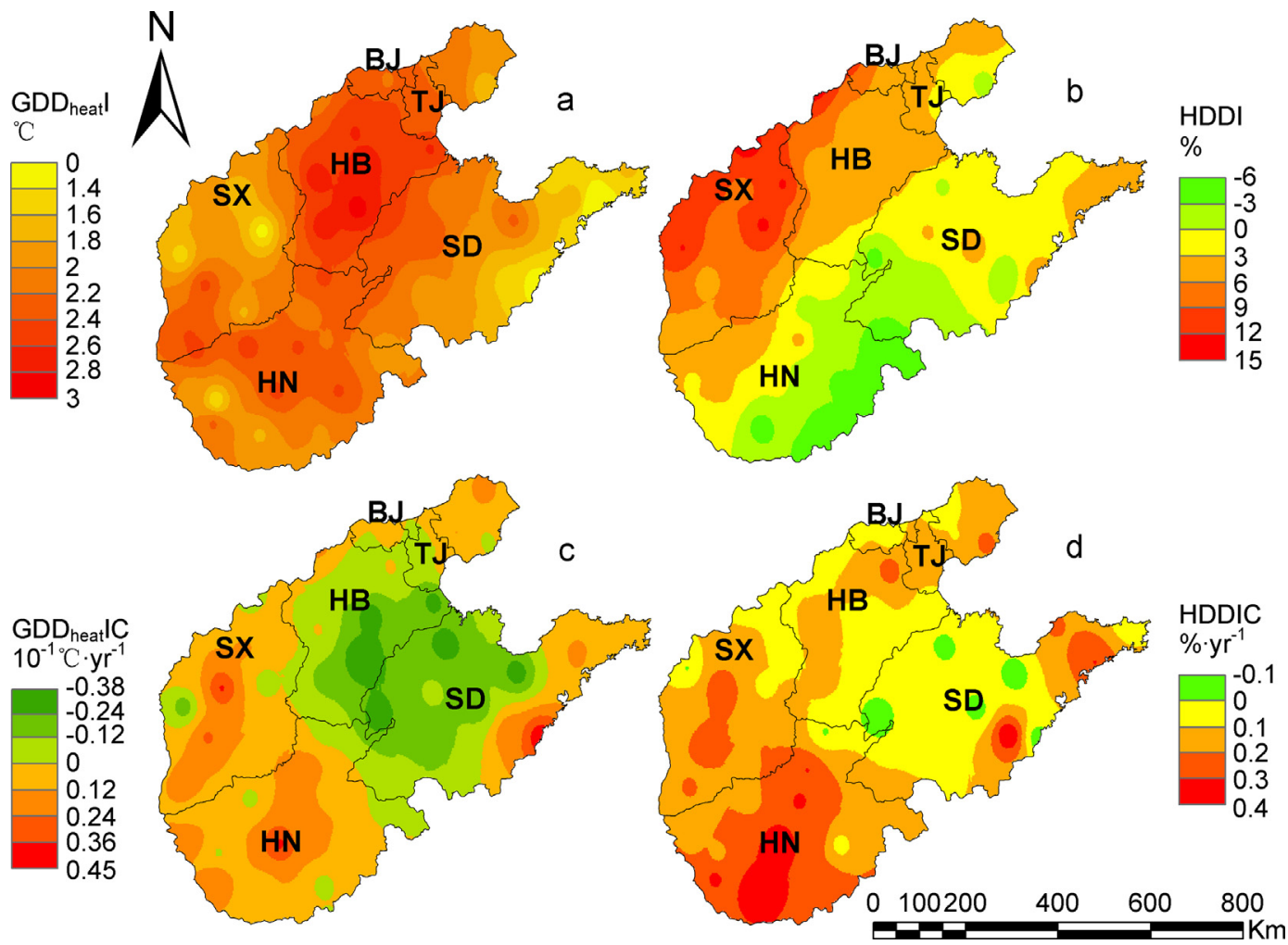

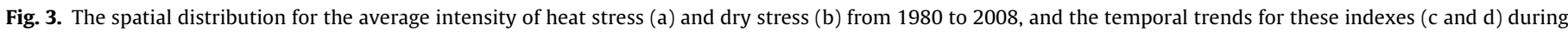
the same period.

Regarding the temporal trends for heat stress and dry stress, distinct regional characteristics are observed in Fig. $2 \mathrm{c}$ and $\mathrm{d}$ and
Fig. $3 \mathrm{c}$ and d. For heat stress, a significant decrease could be found in the central region of the research area. Most portions of $\mathrm{HB}, \mathrm{SD}$ 


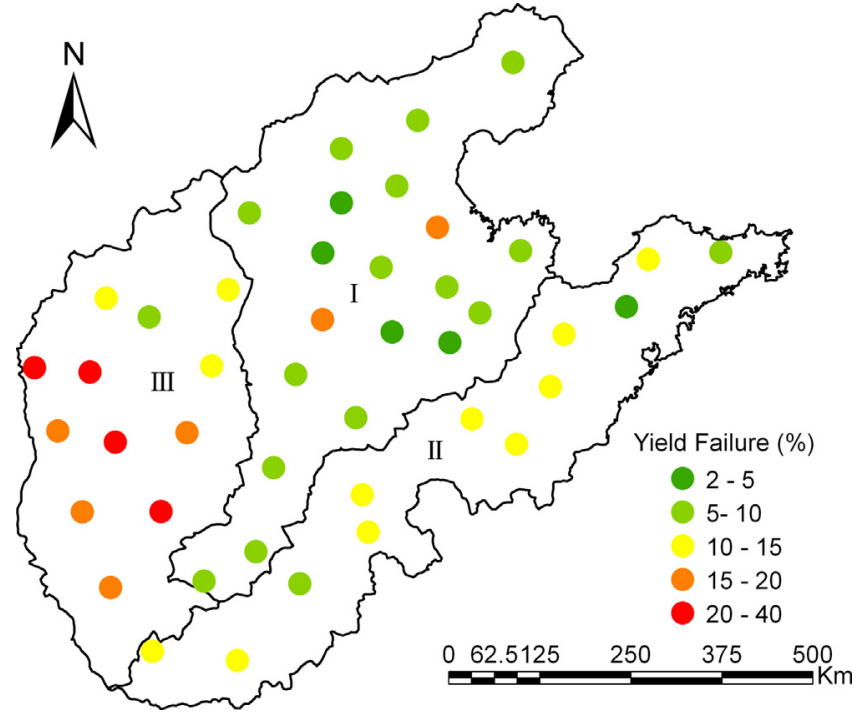

Fig. 4. The local-specific average yield failures from 1980 to 2008.

and the east part of HN have experienced decreased heat stress with a rate of less than $0.7^{\circ} \mathrm{C} \mathrm{dyr}^{-1}$ and $0.038^{\circ} \mathrm{Cyr}^{-1}$ for $\mathrm{GDD}_{\text {heat }}$ and $\mathrm{GDD}_{\text {heat }} \mathrm{I}$, respectively. Meanwhile, larger values (mainly 0.3 to $0.9{ }^{\circ} \mathrm{C} \mathrm{d} \mathrm{yr}^{-1}$ for $\mathrm{GDD}_{\text {heat }}$ ) in the west and southwest region suggested rapid increases in exposure to heat stress for local winter wheat production.

However, for dry stress, HDD and HDDI increased throughout the research area in the past decades. The slight decreasing trends for HDD $\left(-2-0 \% \mathrm{~d} \mathrm{yr}^{-1}\right)$ occurred only in few areas, mainly in the SD province, while the sharp increases $\left(>3 \% \mathrm{~d} \mathrm{yr}^{-1}\right)$ were identified in the entire west and southwest regions. The HDDI changes in the HN province were the most worrying because of the ubiquitous increase rates of more than $0.2 \% \mathrm{yr}^{-1}$ (with the maximum of $0.405 \% \mathrm{yr}^{-1}$ ) in heat stress events during the study period.

\subsection{Spatial variation of crop failures}

The crop failures shown in Fig. 4 describe the local specific responses of winter wheat's detrended yields to adverse climate conditions. Larger crop failures were located in the western regions, with the largest average ratio of $39 \%$. Detrended yields in the south, southeast and east, mainly marked by yellow dots, experienced less crop failure than that in the west. The counties with crop failure less than $10 \%$ were generally located in the central and northern regions, with a minimum value of $2.37 \%$. According to the observed spatial diversity, we classified the research region into three subregions. Subregion I (mainly in the central and north) were the areas where counties' yield failures were always less than $10 \%$. The counties with failure ratios of $10-15 \%$ were in subregion II (mainly located in the south, southeast and east regions). Areas with more severe failures in the west were classified as subregion III (Fig. 4). According to Yang and Zhu's definition for the adaption ability of local agricultural sectors (Yang et al., 2013), subregion I could be classified into a higher level for its adaptation ability to natural disasters because of its lower value of crop failure compared to subregion II and III.

\subsection{Sensitivity of winter wheat yield to $G D D_{\text {heat }}$ and $H D D$}

Based on the results of linear correlation analyses, only counties with significant $(P<0.05)$ correlation are shown in Fig. 5a. The negative coefficients could be observed in all of these counties,
Table 1

Coefficients and $R^{2}$ for multiple linear regression models of $\mathrm{GDD}_{\text {heat }}$ and HDD to yield fluctuation at regional scales.

\begin{tabular}{llll}
\hline Subregion & GDD $_{\text {heat }}$ & HDD & $R^{2}$ \\
\hline I & -0.098 & -0.011 & $0.060^{* *}$ \\
II & -0.168 & -0.033 & $0.095^{* *}$ \\
III & -0.248 & -0.060 & $0.101^{* *}$ \\
Entire research region & -0.143 & -0.027 & $0.066^{* *}$
\end{tabular}

${ }^{* *}$ Indicates significance at $P<0.01$.

suggesting ubiquitous negative relationships between yield fluctuation and both extreme climatic indexes.

Based on multiple linear regressions, the spatial patterns of sensitivity of winter wheat yield to climate variables are shown in Fig. 5b and c. The coefficients for counties with significant regression and correlation $(P<0.05)$ results are shown (the $R^{2}$ of these counties were between 0.25 and 0.35 ). The results showed that winter wheat production in most of the sample counties in subregion II and III were influenced significantly by extreme climate variables. However, weaker impacts were detected in subregion I. Additionally, as for $\mathrm{GDD}_{\text {heat }}$ (Fig. 5b), higher sensitivities were observed among counties in the north of subregion III, with the largest sensitivity of -4.4 . This result suggests that the increase of $1{ }^{\circ} \mathrm{Cd}$ for annual heat stress would lead to a yield reduction of $4.4 \%$. Sensitivities in subregion I and II were relatively lower than those in subregion III, and sensitivities in subregion II were relatively higher than those in subregion I. Most of the coefficients in these two subregions were larger than -0.5 , indicating a slight yield loss $(<0.5 \%$ yield $\left.\left({ }^{\circ} \mathrm{Cd}\right)^{-1}\right)$ when suffering from $\mathrm{GDD}_{\text {heat }}$ increases. Regarding the influence of HDD, higher sensitivities with coefficients smaller than -0.05 were generally concentrated in subregion II and the southern parts of the other two subregions (Fig. 5c). The smallest coefficient of -0.24 suggested the highest sensitivity which meant the yield loss of $0.24 \%$ with $1 \% d$ increase in HDD. Meanwhile, the sensitivity in the central and eastern regions of subregion I were less obvious, with coefficients between 0 and -0.05 . In most parts of subregion I and III, no evident responses of yield to HDD were detected (Fig. 5c).

Analyses on the subregional scale are based on the data in all of the sample counties in one subregion. For the three subregions, the significant negative associations between $\mathrm{GDD}_{\text {heat }}$, HDD and detrended yields have been strongly substantiated (Fig. 6). The results of multiple linear regression models on subregional scales show the significant combined influences of GDD heat and HDD on winter wheat yield (Table 1). The lowest sensitivity to heat stress and dry stress were observed in subregion I, while the sensitivity in subregion III was the largest. Both climate indexes showed negative coefficients to the winter wheat yield in all three subregions and the whole research area, supporting the generally negative influences of both indexes.

\subsection{Contribution of climate indexes to winter wheat yield}

Based on the temporal trends of GDD $\mathrm{Geat}_{\text {he }}$ and HDD from 1980 to 2008 , and the sensitivities of winter wheat yield to these indexes, the historical contribution of climate change on the county-level yield were comprehensively evaluated (Fig. 7a-c). The winter wheat production in the west, southwest and north experienced a yield loss of up to $1.28 \%$ per year because of the increase of $G_{D D}$ heat . However, the winter wheat cultivated in the central and eastern areas substantially benefited from the reduction of $\mathrm{GDD}_{\text {heat }}$, with a yield increase of up to $0.3 \%$ per year (Fig. $7 \mathrm{a}$ ). Regarding the contribution of HDD, counties with decreased HDD in the past 30 years witnessed an increasing yield of approximately $0.1 \%$ per year, while the increase of HDD has led to yield loss of $0.1-0.35 \%$ per year in 

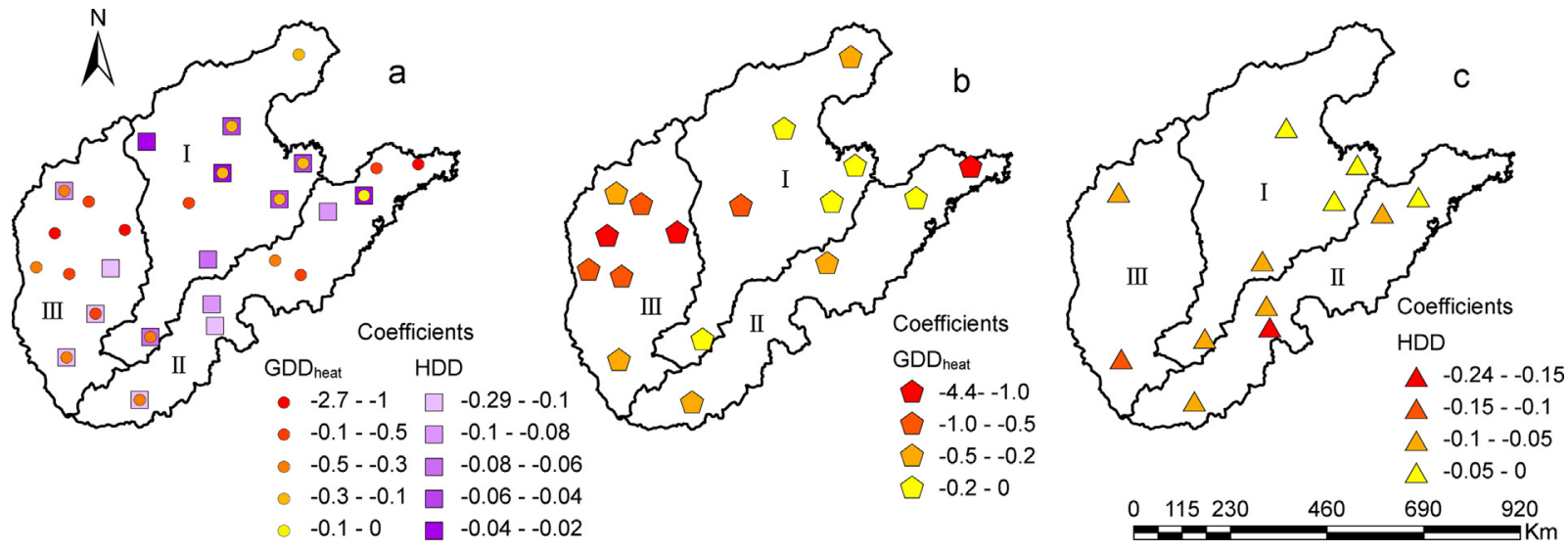

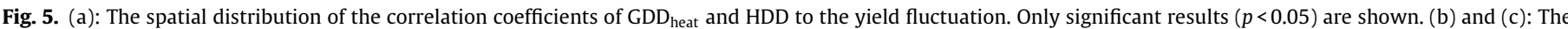

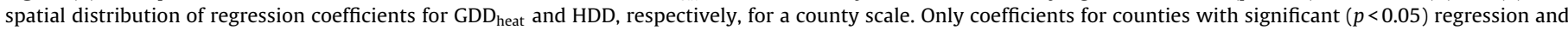
correlation results are shown.

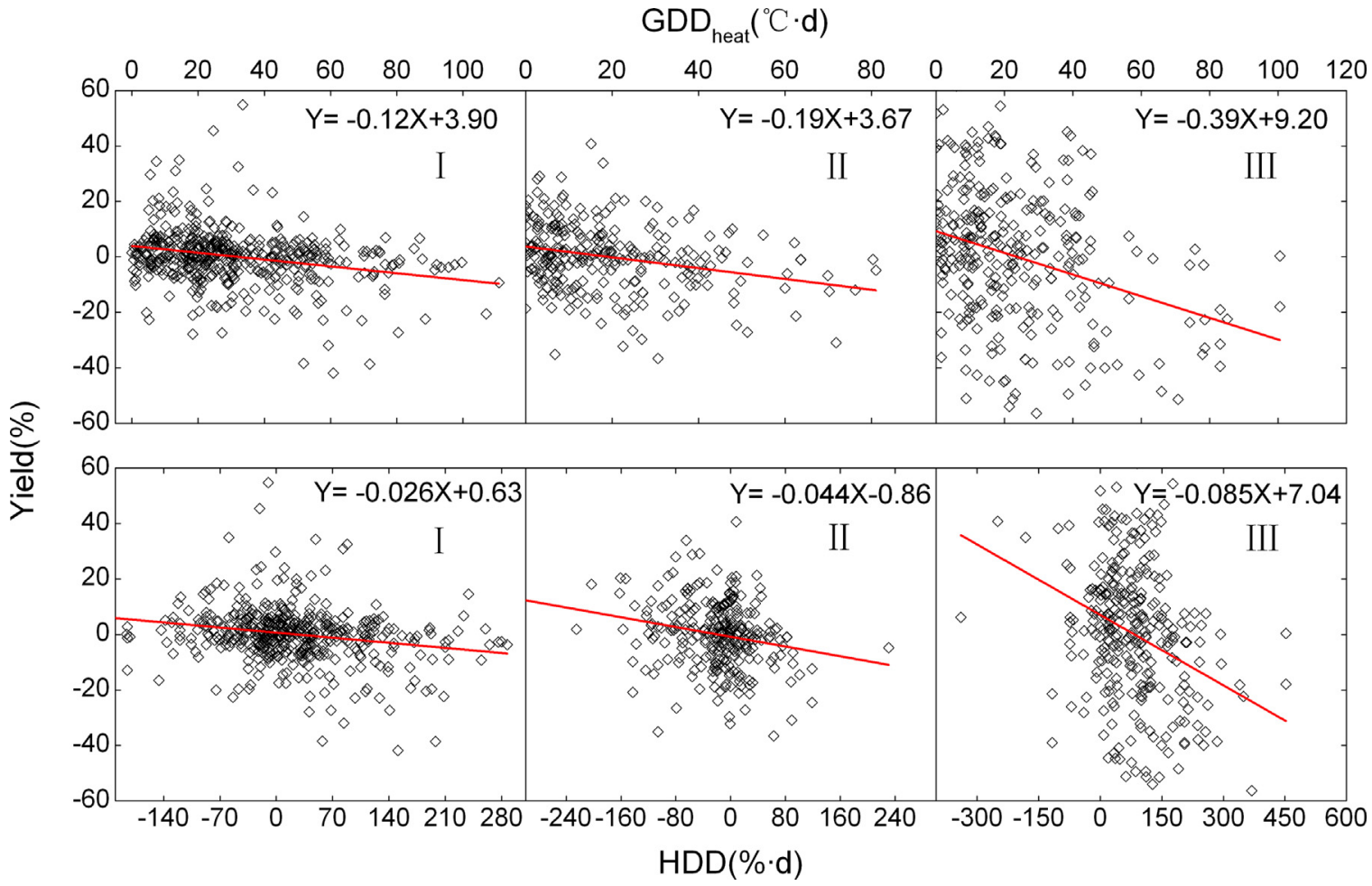

Fig. 6. Linear regressions for the fitting of the correlation of $\mathrm{GDD}_{\text {heat }}$ or HDD to the yield fluctuation in three subregions.

lower latitudes (Fig. 7b). Overall, the contribution of both indexes (Fig. 7c) resulted in yield losses in most portions of research area, especially in the west and south. Yield increases in some counties in the central and eastern regions were observed. However, these ratios of increases were much lower than those of yield losses in other areas.

\section{Discussion}

\subsection{Climatic risk in northern China}

As one of the severe threats to winter wheat production in northern China, dry-hot wind disasters highlight the importance of focusing on impacts from multi-hazards. Using climate records, phenology and winter wheat yield datasets at county scale during the past few decades in northern China, we analysed the charac- teristics of heat stress and dry stress from the heading to maturity stages, and their impacts on winter wheat yield.

As a prevalent extreme climatic hazard, heat stress has attracted increasing attentions worldwide in recent years (Asseng et al., 2011; Semenov and Shewry, 2011; Teixeira et al., 2013; Asseng et al., 2015). Our results on spatial distributions substantiated higher heat stresses in the central and northern areas of study region, suggesting a higher exposure to extreme high temperature for winter wheat growth than in other regions. However, the temporal decrease of $\mathrm{GDD}_{\text {heat }}$ in the central and eastern regions represented the mitigation of such adverse impacts over the past 30 years. In addition to the decrease in some areas, a rapid increase of $\mathrm{GDD}_{\text {heat }}$ appeared in the west, suggesting that the high risk areas for heat stress between the heading stage and maturity stage have shifted from HB and SD to SX and HN. Additionally, the increased $\mathrm{GDD}_{\text {heat }}$ in $\mathrm{BJ}, \mathrm{TJ}$ and east SD, although not as sharp as that in the 

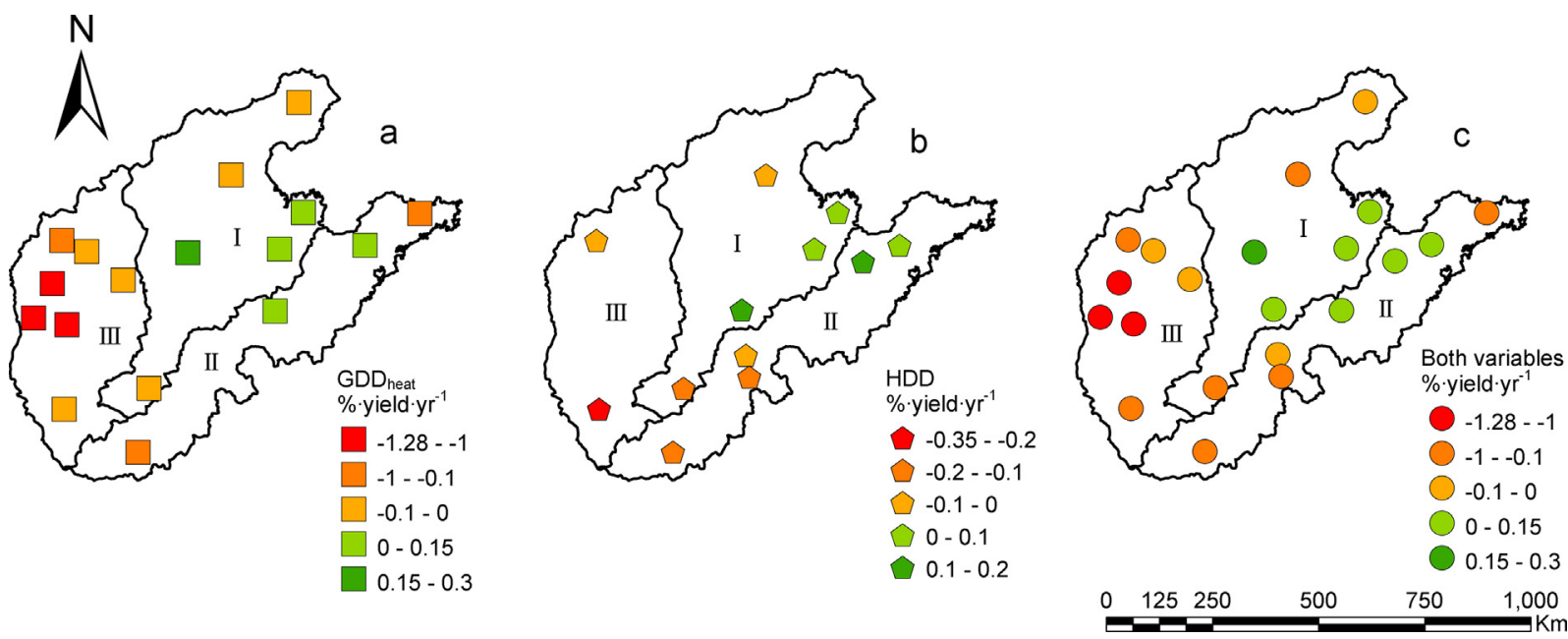

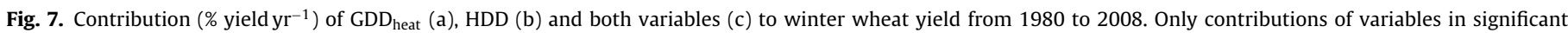
counties in Fig. 5(b and c) are shown.

west, suggested the intensification of localized heat stress exposure in the past few decades.

Compared to the increasing focuses on heat stress, attention to the dry stress accompanying a hot event was always insufficient. In addition to the severe influence of heat stress, dry stress could simultaneously inhibit crop production and aggravate the impacts of extreme events. Thus, we should pay more attentions to this climatic variable. In this study, the wetter trend from north to south indicated the reduction of exposure to dry stress in spatial pattern (Fig. 2b). In the south, the favorable humidity avoided the green wilting (which always manifested as rapid water loss and crop withering in a short time) from extreme dry stress or shorter filling duration caused by extreme high humidity and high temperature (Liu et al., 2014). The dry stress in the north during heat stress could incontrovertibly pose a threat to winter wheat growth. A consistent dryer trend in nearly the whole region brought a ubiquitous and increasingly serious threat to agricultural production. This state strongly substantiated that the global warming has aggravated the water shortage and led to increasingly severe dry stress in northern China. Additionally, the inconsistent trends between heat and dry stress highlighted the complexity of climate systems, suggesting that the critical hazard may vary in different areas. Therefore, it is essential and necessary to assess comprehensively and scientifically the risk of multiple climatic hazards.

\subsection{Impacts of multiple climatic hazards on winter wheat yield}

The crops are often subject to combinations of stress factors that affect their growth and development (Porter and Semenov, 2005; Lobell et al., 2013). Thus considering impacts of multi-hazards is necessary and urgent since incomplete risk analysis may lead to the underestimate on potential influences (Trnka et al., 2014). The negative relationships between $\mathrm{GDD}_{\text {heat }}$, HDD and winter wheat yield were observed at both county and subregion levels, indicating the ubiquitous adverse influence of extreme climatic variables on winter wheat yield, and the benefits from favorable climate conditions in promoting agricultural production. Additionally, the contributions of heat and dry stress to winter wheat yield (Fig. 7a and b) have substantiated that the historical deterioration of these two hazards during the post-heading stages significantly restricted the development of winter wheat production in most parts of northern China in the past 30 years. The restriction to winter wheat production in subregion III was mainly attributed to heat stress, while the yield loss in the south of subregion I and II was caused more by dry stress. Therefore, both heat stress and dry stress are key obstacles for reaching the potential ceiling of winter wheat yield, highlighting the necessity of focusing on the influences of local-specific key variables. Although the decrease of stresses in some areas improved the detrended yield, the negative impact of these variables on wheat yield is obvious in nearly the entire northern China (Fig. 7c). These findings stress that the two hazards have resulted in a severe threat to agricultural production and food supply security. Moreover, some areas experienced negative influences of both hazards, suggesting the urgent need of considering combined impacts from multiple hazards.

In addition to the impacts obtained from statistical analyses, we also found that the impacts of climatic hazards were not determined directly by their exposures. When comparing the observed spatial patterns between the sensitivity and exposures to hazards, higher sensitivities were always associated with relative lower climatic stresses (Figs. 2a and b, 5). For example, the higher sensitivities to $\mathrm{GDD}_{\text {heat }}$ in subregion II and III coincided with the exposure of less than $25^{\circ} \mathrm{Cd}$. The winter wheat yield had the highest sensitivities to HDD in the south, where the climate condition is wetter, however the HDD played less roles in the drier north of northern China. Additionally, sensitivities to $\mathrm{GDD}_{\text {heat }}$ and HDD in the central and eastern areas of subregion I were generally low, even though the highest heat and the second highest dry stress occurred in this area. These opposite spatial patterns between exposure and sensitivities indicated that the yield fluctuations did not respond simply to climatic hazards. To evaluate further other factors controlling wheat yield, we should account for mitigation and adaptation measures, which strongly influenced the vulnerability of crop in northern China.

\subsection{Effects and improvement potential of the adaptation in northern China}

The risk of climate hazards on yield results from the interaction of climate related hazards with the vulnerability and exposure, which are drived by socioeconomic processes such as adaptation and mitigation (IPCC, 2014). The actions of adjusting practices or adaptation strategies to extreme climate events can largely dominate the agricultural production (Smit and Skinner, 2002; Rosenzweig and Tubiello, 2007; Fosu-Mensah et al., 2012). Generally, local managers and farmers will design adaptation measures according to the crop exposure to adverse climatic hazards and past risk management experience. Considering the demands of 
food supply security in government level and profits of farmers, it was not surprising that adaptation measures would be widely adopted to mitigate the potential yield loss. The higher exposure to hazards would promote the adaptive capacity for defending them, and the effective adaptation would reduce the vulnerability of crops and lead to the low sensitivities in areas with high exposures (Rosenzweig and Tubiello, 2007; Reidsma et al., 2010). On the contrary, the concurrence of higher sensitivities and lower exposures might be resulted from insufficient adaptive capacity and high vulnerability. The lower sensitivity is generally considered as a weaker dependence of crop production on climatic conditions, which would lead to more stable wheat yield. Thus, the more effective adaptation could reduce the uncertainty of yield caused by climate changes or climatic hazards, and promote reaching its potential yield with advanced technology. However, for areas suffered from high vulnerability, improvement of adaptation was in urgent need. Specifically in this study, the opposite spatial patterns between exposure and sensitivities implied the well-developed adaptation in central and eastern parts of subregion I, as well as the adaptation insufficiency in subregion II and III (for GDD heat) and the south and southeast parts of the study area (for HDD).

Adaptations can be taken in scales from local field to macroscopic policy. Actually, some famers have already adapted themselves to climate change by altering the cultivars or sowing time (Fujisawa and Kobayashi, 2010). However, adaptive responses from farmers have been pointed out as simple and not ubiquitous (Bryan et al., 2009). Moreover, the effects are various because of different barriers to adaptation such as capital lack and technology unavailable (Fisher et al., 2015). Although the adaptations from profit-seeking farmers would bring benefits to crop yield in some degrees (Lobell, 2014), effective adaptation in regional scale often required the power from policies to help build and strengthen the favorable conditions (financial or social factors) for mitigating the negative impacts from climate hazards (Porter et al., 2014). Adaptation strategies conducted by decision-makers could involve multiple scales (Nelson et al., 2008), and further result in regional specific responses in facing the impacts of climate hazards.

Our study has revealed the differences of adaptation among regions. The regional diversity may result from various socialeconomic factors such as financial factors, infrastructure, and inadequate knowledge about the risk of climate hazards (IPCC, 2014), and all these factors will strongly influence the application of adaptation actions. For example, because of the significant adaptation potential of irrigation for wheat (Piao et al., 2010), different irrigation capacity will result in large gaps on adaptation. In field management, the water available and environment could both influence the development of irrigation. Given the drier environment in the north of our study area, the inputs on irrigation was larger than those in the south, while the water shortage in the west also limited the effects of irrigation. Meanwhile, the historical financial inputs of agriculture management, technologies and infrastructure in the central and eastern parts were much larger than that in the west because of their important roles in food supply security in China. All such beneficial factors have brought subregion I larger adaptive ability than other subregions, especially than subregion III which has faced the lowest adaptation capacity.

On the other hand, changing climatic system has brought rapidly increasing exposure to crop growth, the inadequate forecast of climate in recent decades may be another reason for the insufficiency in coping with climate extremes and the consequent higher sensitivity of dry stress and heat stress in subregions II and III, respectively. Effective adaptations will reduce the negative impacts of climate hazards and keep the yield more stable (Lobell, 2014). From the standpoint of yield stability, the higher yield failures in subregion II and III have also substantiated the more urgent need to strengthen adaptation in these two subregions than that in subregion $\mathrm{I}$.

Since effects of adaptation in all scales (from farmer to policy) may change the responses of crop to climate conditions, thus considering the exposure alone may mislead the evaluation of the risk. For future risk assessments, analyses only focus on climatic scenarios are not enough. Apart from the accurate assessment of climate extremes, it will be necessary to evaluate integrated effects of adaptations in different scales and their interactions in order to quantify the real impacts of climate change on crop production and food supply security.

As for management practices, we are sure that effective responses to climatic hazards could help agricultural production adapt to the climate changes and mitigate the damage of extreme events (Yang et al., 2007; Park et al., 2012). Additionally, methods, such as new heat/dry-resistant varieties, chemical spraying, water diversion and advanced irrigation technologies, have been in well development in China, providing potential adaptation strategies to mitigate the adverse influence from extreme climate conditions. In order to improve the regional adaptation, efforts from multiple sectors are highly required (Adger et al., 2009). Firstly, regional climate forecasting is essential to support information for decision-making on adaptation, then, sufficient inputs into constructing infrastructure of irrigation, introducing better varieties and advanced management technologies to farmers should be top duties of government. Meanwhile, spontaneous adaptation of farmers should be encouraged and guided to match their profit demands. Moreover, considering the diversity of adaptive capacity among different subregions, improvement in subregion III should be high priority. On the other hand, sharing experiences among regions/counties will also be beneficial for speeding up the adaptation progress. The efficient application of such positive measures will be critical to solve the current deficiency in adaptation and cope with the extreme climate risk in the future.

\section{Conclusions}

As the main production area for winter wheat, the agricultural production in northern China is closely tied to national food supply security. Using historical climate data, phenology data and yield records in the past 30 years, this study analysed the spatio-temporal variability of heat stress and dry stress between the heading and maturity stages, and their impacts on winter wheat production over the past few decades.

The observed spatial results indicated higher heat stresses in the central and northern regions, and dryer environments in the northwestern and northern parts of northern China. Regarding temporal trends, we found an increase of heat stress in the west and an overall aggravation of dry stress in the entire northern China. Statistical analyses indicated significant negative influences of heat stress and dry stress on winter wheat yield. The deterioration of these two extreme climate variables contributed to significant yield losses during the study period. These results emphasized the importance of concerning multi-hazards and local-specific hazards instead of one prevalent climate variable when assessing the influence of extreme events on yield. Additionally, the comparisons between exposure and sensitivities revealed that yield fluctuation of winter wheat does not simply respond to climate conditions, suggesting the critically positive effects of agricultural adaptation strategies in reducing the impacts of extreme events and climate changes. This study highlights the necessity of improving practical agricultural adaptation inputs to cope with the potential risks, and focusing on adaptive capacity in future risk evaluations to address the real threat from climate changes. 


\section{Acknowledgments}

This study was funded by the National Natural Science Foundation of China (Nos. 41321001; 41571493; 41571088, 31561143003), The Programme of Introducing Talents of Discipline to Universities (B08008), and the State Key Laboratory of Earth Surface Processes and Resource Ecology, Beijing Normal University.

\section{References}

Adger, W.N., Dessai, S., Goulden, M., Hulme, M., Lorenzoni, I., Nelson, D., Naess, L., Wolf, J., Wreford, A., 2009. Are there social limits to adaptation to climate change? Clim. Change 93 (3-4), 335-354.

Akaike, H., 1974. A new look at the statistical model identification. IEEE Trans. Autom. Control 19 (6), 716-723.

Asseng, S., Foster, I., Turner, N.C., 2011. The impact of temperature variability on wheat yields. Global Change Biol. 17 (2), 997-1012.

Asseng, S., Ewert, F., Martre, P., Rötter, R.P., Lobell, D.B., Cammarano, D., Kimball B.A., Ottman, M.J., Wall, G.W., White, J.W., 2015. Rising temperatures reduce global wheat production. Nat. Clim. Change 5 (2), 143-147.

Bryan, E., Deressa, T.T., Gbetibouo, G.A., Ringler, C., 2009. Adaptation to climate change in Ethiopia and South Africa: options and constraints. Environ. Sci. Policy 12 (4), 413-426.

Cao, L., Dou, Y., 1997. Climate characteristic analysis and forecast of dry-hot wind in Central Hexi Corridor. Agric. Res. Arid Areas 03, 99-105 (in Chinese with English abstract).

Cheng, L., Zhang, Z., Chang, J., 2011. Analysis on the change of dry-hot wind hazard for winter wheat in last 47 years in Henan Province. Chin. J. Agrometeorol. 03. 456-465 (in Chinese with English abstract).

Decker, W.L., 1994. Developments in agricultural meteorology as a guide to its potential for the twenty-first century. Agric. For. Meteorol. 69 (1), 9-25

Deng, Z., Xu, J., Huang, L., Zhang, S., 2009. Research summary of the damage characteristics of the wheat dry hot wind in Northern China. J. Anhui Agric. Sci. 20, 9575-9577 (in Chinese with English abstract)

Deryng, D., Conway, D., Ramankutty, N., Price, J., Warren, R., 2014. Global crop yield response to extreme heat stress under multiple climate change futures. Environ. Res. Lett. 9 (3), 034011.

FAO, 2012. Statistical Yearbook : World Food and Agriculture. FAO (Food and Agriculture Organziation of the United Nations), Rome, pp. 184.

Fisher, M., Abate, T., Lunduka, R.W., Asnake, W., Alemayehu, Y., Madulu, R.B., 2015 Drought tolerant maize for farmer adaptation to drought in sub-Saharan Africa: determinants of adoption in eastern and southern Africa. Clim. Change, 1-17.

Fosu-Mensah, B.Y., Vlek, P.L., MacCarthy, D.S., 2012. Farmers' perception and adaptation to climate change: a case study of Sekyedumase district in Ghana. Environ. Dev. Sustainibility 14 (4), 495-505.

Fujisawa, M., Kobayashi, K., 2010. Apple (Malus pumila var. domestica) phenology is advancing due to rising air temperature in northern Japan. Global Change Biol. 16 (10), 2651-2660.

Gourdji, S.M., Mathews, K.L., Reynolds, M., Crossa, J., Lobell, D.B., 2013. An assessment of wheat yield sensitivity and breeding gains in hot environments. Proc. R. Soc. B. Biol. 280 (1752), 20122190.

IPCC, 2012. Managing the Risks of Extreme Events and Disasters to Advance Climate Change Adaptation: Special Report of the Intergovernmental Panel on Climate Change. Cambridge University Press, UK.

IPCC, 2014. Climate Change 2014: Impacts, Adaptation, and Vulnerability. Part A: Global and Sectoral Aspects. In: Field, C.B., Barros, V.R., Dokken, D.J., Mach, K.J. Mastrandrea, M.D., Bilir, T.E., Chatterjee, M., Ebi, K.L., Estrada, Y.O., Genova, R.C., Girma, B., Kissel, E.S., Levy, A.N., MacCracken, S., Mastrandrea, P.R., White, L.L. (Eds.), Contribution of Working Group II to the Fifth Assessment Report of the Intergovernmental Panel on Climate Change. Cambridge University Press, Cambridge, United Kingdom and New York, NY, USA.

Li, S., Wheeler, T., Challinor, A., Lin, E., Ju, H., Xu, Y., 2010. The observed relationships between wheat and climate in China. Agric. For. Meteorol. 150 (11), 1412-1419.

Liu, D., Sun, L., Ning, H., 2008. Characteristics of dry-hot wind in Gansu Province and its response to climate change. J. Glaciol. Geocryol. 01, 81-86 (in Chinese with English abstract).

Liu, B., Liu, L., Tian, L., Cao, W., Zhu, Y., Asseng, S., 2014. Post-heading heat stress and yield impact in winter wheat of China. Global Change Biol. 20 (2), 372-381.

Lobell, D.B., Schlenker, W., Costa-Roberts, J., 2011. Climate trends and global crop production since 1980. Science 333 (6042), 616-620.

Lobell, D.B., Hammer, G.L., McLean, G., Messina, C., Roberts, M.J., Schlenker, W., 2013. The critical role of extreme heat for maize production in the United States. Nat. Clim. Change 3 (5), 497-501.

Lobell, D.B., 2014. Climate change adaptation in crop production: beware of illusions. Global Food Secur. 3 (2), $72-76$.
National Bureau of Statistics of China, 2011. China Statistical Yearbook 2011. China Statistics Press, Beijing.

Nelson, R., Howden, M., Smith, M.S., 2008. Using adaptive governance to rethink the way science supports Australian drought policy. Environ. Sci. Policy 11 (7), 588-601.

Park, S.E., Park, S.E., Marshall, N.A., Jakku, E., Dowd, A.M., Howden, S.M., Mendham, E., Fleming, A., 2012. Informing adaptation responses to climate change through theories of transformation. Global Environ. Change 22 (1), 115-126.

Piao, S., Ciais, P., Huang, Y., Shen, Z., Peng, S., Li, J., Zhou, L., Liu, H., Ma, Y., Ding, Y., 2010. The impacts of climate change on water resources and agriculture in China. Nature 467 (7311), 43-51.

Porter, J.R., Gawith, M., 1999. Temperatures and the growth and development of wheat: a review. Eur. J. Agron. 10 (1), 23-36.

Porter, J.R., Semenov, M.A., 2005. Crop responses to climatic variation. Philos. T. R. Soc. B 360 (1463), 2021-2035.

Porter, J.R., Xie, L., Challinor, A.J., Cochrane, K., Howden, S.M., Iqbal, M.M., Lobell, D.B., Travasso, M.I., 2014. In: Field, C.B., et al. (Eds.), Food Security and Food Production Systems. Cambridge University Press, Cambridge, United Kingdom and New York, NY, USA, pp. 485-533.

Randall, P.J., Moss, H.J., 1990. Some effects of temperature regime during grain filling on wheat quality. Crop Pasture Sci. 41 (4), 603-617.

Rane, J., Nagarajan, S., 2004. High temperature index-for field evaluation of heat tolerance in wheat varieties. Agric. Syst. 79 (2), 243-255.

Ray, D.K., Ramankutty, N., Mueller, N.D., West, P.C., Foley, J.A., 2012. Recent patterns of crop yield growth and stagnation. Nat. Commun. 3, 1293.

Reidsma, P., Ewert, F., Lansink, A.O., Leemans, R., 2010. Adaptation to climate change and climate variability in European agriculture: the importance of farm level responses. Eur. J. Agron. 32 (1), 91-102.

Rosenzweig, C., Tubiello, F.N., 2007. Adaptation and mitigation strategies in agriculture: an analysis of potential synergies. Mitig. Adapt. Strat. Gl. Change 12 (5), 855-873.

Semenov, M.A., Shewry, P.R., 2011. Modelling predicts that heat stress, not drought, will increase vulnerability of wheat in Europe. Sci. Rep. UK 1

Semenov, M.A., Mitchell, R.A., Whitmore, A.P., Hawkesford, M.J., Parry, M.A., Shewry, P.R., 2012. Shortcomings in wheat yield predictions. Nat. Clim. Change 2 (6), 380-382.

Smit, B., Skinner, M.W., 2002. Adaptation options in agriculture to climate change: a typology. Mitig. Adapt. Strat. Gl. Change 7 (1), 85-114.

Stone, P.J., Nicolas, M.E., 1994. Wheat cultivars vary widely in their responses of grain yield and quality to short periods of post-anthesis heat stress. Funct. Plant Biol. 21 (6), 887-900.

Tao, F., Zhang, Z., Zhang, S., Zhu, Z., Shi, W., 2012. Response of crop yields to climate trends since 1980 in China. Clim. Res. 54, 233-247.

Tao, F., Zhang, S., Zhang, Z., 2013. Changes in rice disasters across China in recent decades and the meteorological and agronomic causes. Reg. Environ. Change 13 (4), 743-759.

Teixeira, E.I., Fischer, G., van Velthuizen, H., Walter, C., Ewert, F., 2013. Global hot-spots of heat stress on agricultural crops due to climate change. Agric. For. Meteorol. 170 (0), 206-215.

Trnka, M., Rötter, R.P., Ruiz-Ramos, M., Kersebaum, K.C., Olesen, J.E., Žalud, Z., Semenov, M.A., 2014. Adverse weather conditions for European wheat production will become more frequent with climate change. Nat. Clim. Change 4 (7), 637-643.

Ugarte, C., Calderini, D.F., Slafer, G.A., 2007. Grain weight and grain number responsiveness to pre-anthesis temperature in wheat, barley and triticale. Field Crops Res. 100 (2), 240-248.

Wang, P., Zhang, Z., Song, X., Chen, Y., Wei, X., Shi, P., Tao, F., 2014. Temperature variations and rice yields in China: historical contributions and future trends. Clim. Change, 1-13.

Yang, X., Lin, E., Ma, S., Ju, H., Guo, L., Xiong, W., Li, Y., Xu, Y., 2007. Adaptation of agriculture to warming in Northeast China. Clim. Change 84 (1), 45-58.

Yang, F., Zhu, Y., Liu, W., 2013. Occurrence rules and risk zoning of dry-hot wind in winter wheat producing areas of north China. J. Nat. Disasters 3, 112-121 (in Chinese with English abstract).

Zhang, T., Zhu, J., Wassmann, R., 2010. Responses of rice yields to recent climate change in China: an empirical assessment based on long-term observations at different spatial scales (1981-2005). Agric. For. Meteorol. 150 (7), 1128-1137.

Zhang, T., Yang, X., Wang, H., Li, Y., Ye, Q., 2014. Climatic and technological ceilings for Chinese rice stagnation based on yield gaps and yield trend pattern analysis. Global Change Boil. 20 (4), 1289-1298.

Zhang, Z., Chen, Y., Wang, P., Zhang, S., Tao, F., Liu, X., 2014a. Spatial and temporal changes of agro-meteorological disasters affecting maize production in China since 1990. Nat. Hazards 71 (3), 2087-2100.

Zhang, Z., Wang, P., Chen, Y., Zhang, S., Tao, F., Liu, X., 2014b. Spatial pattern and decadal change of agro-meteorological disasters in the main wheat production area of China during 1991-2009. J. Geogr. Sci. 24 (3), 387-396.

Zhang, Z., Zhang, Z., Wang, P., Chen, Y., Song, X., Wei, X., Shi, P., 2014c. Global warming over 1960-2009 did increase heat stress and reduce cold stress in the major rice-planting areas across China. Eur. J. Agron. 59, 49-56. 